\title{
INCIDÊNCIA DE SÍNDROME CÓLICA OCASIONADAS POR CORPOS ESTRANHOS EM CAVALOS CARROCEIROS DE CURITIBA
}

(Incidence of colic syndrome caused by foreign bodies in carthorses of Curitiba)

Monalisa Lukascek Castro, Frederico Fernandes Araújo, Jéssica Rodrigues da Silva, Luciane Maria Laskoski, Ricardo Guilherme D'Otaviano de Castro Vilani, Peterson Triches Dornbusch ${ }^{1}$

${ }^{1}$ Correspondência: monalukaa@gmail.com

RESUMO: As obstruções ocasionadas por corpos estranhos em equinos de tração são causadoras de síndrome cólica. Nestes animais esta incidência dá-se ao fato destes viverem em locais de más condições sanitárias e possuírem manejo nutricional ineficiente. $O$ presente trabalho relata os achados de corpos estranhos intestinais ocasionando síndrome cólica em seis animais atendidos no Hospital Veterinário da Universidade Federal do Paraná. Foram encontrados nos animais sacos plásticos e enterólitos em cólon menor, cólon maior, reto ou cólon transverso. A resolução foi cirúrgica para cinco animais e clínica em um. Demonstra-se a incidência de obstruções causadas pela ingestão de corpos estranhos nestes animais, enfatizando suas causas, principais locais e os métodos de diagnóstico auxiliares. A frequência de desconforto abdominal devido esta causa mostrou-se alta devido ao erro de manejo destes.

Palavras-chave: afecções gastrintestinais; celiotomia; desconforto abdominal; equinos de tração

ABSTRACT: Foreign body obstructions are a common cause of colic in carthorses. The high incidence may be due to poor feeding practices and to the fact that most of these animals live in inadequate sanitary conditions. This paper reports six cases of colic caused by foreign bodies in carthorses presented to the Veterinary Teaching Hospital of the Federal University of Paraná. Plastic bags and enteroliths were found in the small colon, large colon, transverse colon and rectum. All animals presented abdominal discomfort and hypotonicity. Five horses underwent surgery and one was treated medically. The paper emphasizes the importance of auxiliary diagnostic methods the mainly affected portions of the intestine and the risk factors associated to the colic syndrome.

Key Words: abdominal pain; carthorses; celiotomy; enteroliths; gastrointestinal disordes 


\section{INTRODUÇÃO}

Cavalos carroceiros são considerados um problema socioambiental, principalmente pela alimentação baseada em resíduos de alimentos, carga de exercício intensa, pouco descanso e baixa reposição energética e hídrica na maioria dos animais. A síndrome cólica nestes indivíduos é frequente, sendo relatada no interior de Minas Gerais uma incidência em cerca de 18\% dos animais (Oliveira et al., 2007).

A síndrome cólica, ou abdômen agudo, é uma das principais causas de problemas gastrointestinais em cavalos, representando $50 \%$ das causas de morte em animais adultos (Gonçalves et al, 2002). A obstrução intestinal ocasionada pela ingestão de corpos estranhos é uma das causas da cólica equina, comumente observada em indivíduos jovens. No entanto, adultos também podem ser acometidos (Dearo et al., 2009; Ferreira et al., 2009). O cólon menor é principal local de alojamento de corpos estranhos e o tratamento de eleição é cirúrgico (Dearo et al., 2009).

Levando em conta todas estas considerações, objetivou-se com este artigo demonstrar a frequente incidência de síndrome cólica ocasionada pela ingestão de corpos estranhos em cavalos de tração da cidade de Curitiba, enfatizando a causa primária de obstrução intestinal nestes animais, os principais locais onde corpos estranhos foram localizados e os métodos de diagnóstico auxiliares.

\section{MATERIAL E MÉTODOS}

Entre janeiro de 2011 e dezembro de 2014, 624 cavalos carroceiros foram atendidos no Hospital Veterinário da Universidade Federal do Paraná por meio do projeto de extensão
"Carroceiros". Quinze indivíduos (2,4\%) apresentavam afecções do aparelho digestório, e destes, nove $(1,4 \%)$ demonstraram sinais clínicos inerentes à síndrome cólica. Em seis animais $(1,0 \%)$ foi diagnosticado presença de corpo estranho intestinal, sendo cinco machos castrados e uma fêmea.

A mediana da idade dos animais foi de 3 anos (2-20 anos), e todos eles eram sem raça definida. A obstrução intestinal nos animais foi ocasionada por emaranhado de sacolas plásticas e/ou enterólito, esta encontrada em dois cavalos exclusivamente no reto, cólon menor em dois animais, cólon transverso em e em outro tanto no cólon maior quanto no cólon menor. Dos seis pacientes, quatro tinham como principal sinal clínico dor leve, e dois dor moderada. Foi observado também ao exame físico elevação da frequência cardíaca em cinco animais, e hipotonicidade intestinal à auscultação em todos os animais.

Em três casos o corpo estranho foi diagnosticado por palpação retal, dois deles alojados no reto e o outro no cólon menor. No único animal submetido a avaliação ultrassonográfica foi confirmada a presença de corpo estranho no cólon maior. Cinco passaram por procedimento cirúrgico para retirada dos corpos estranhos e em um dos animais onde as sacolas estavam alojadas no reto obteve resolução clínica.

\section{RESULTADOS E DISCUSSÃO}

Grande parte dos equinos de
tração apresentam alterações fisiopatológicas decorrentes do excesso de trabalho, falta de manejo higiênicosanitário e alimentar adequados (Andrade et al., 2009). Inúmeros animais atendidos pelo projeto de extensão "Carroceiros" da Universidade Federal do Paraná apresentavam 
condições de desnutrição, desidratação, depravação de apetite, apatia entre outras. A dieta destes animais é baseada em milho, restos de feira e capim nativo, vivem em locais com más condições de manejo sanitário, predispondo a ingestão de materiais estranhos na tentativa de reposição da carência alimentar e mineral.

Cavalos atendidos com síndrome cólica por obstrução, apresentavam normalmente dor leve a moderada (Thomassian, 2005), frequência cardíaca levemente aumentada entre 40 e 60 bpm (Ferreira et al., 2008) e ruídos intestinais geralmente presentes, no entanto hipotônicos (Thomassian, 2005; Ferreira et al., 2008), como observados durante exame clínico na maior parte de nossos pacientes.

Poucos cavalos apresentam melhora ao tratamento clínico quando se trata de desconforto abdominal ocasionado pela ingestão de corpo estranho (Doran, 1993), já nos casos de compactação, grande parte dos animais responde ao tratamento clínico realizado com reposição volêmica e eletrolítica, uso de laxantes, fluidoterapia oral e administração parenteral de analgésicos (Ferreira et al., 2008). A ausência de melhoras significativas excluem 0 diagnóstico de compactação simples, sendo indicada a celiotomia exploratória como tratamento de eleição (Thomassian, 2005; Auer e Stick, 2012).

As regiões intestinais comumente acometidas nos casos de obstruções por corpo estranho são flexura pélvica, cólon transverso e cólon menor (Moore, 1990). Neste relato, porém, as sacolas plásticas foram encontradas com maior incidência no reto, cólon menor, seguida de cólon maior (flexura pélvica) e cólon transverso. Corpos estranhos são comumente encontrados em cavalos jovens, com idade inferior a três anos (Dearo et al., 2009; Ferreira et al., 2009; Pierce, 2009), como os animais deste relato, onde cinco tinham idade estimada inferior a três anos.

Os materiais frequentemente encontrados podem ser naturais ou sintéticos como pedaços de saco de ração, cordas, nylon, algodão, raízes e sacolas plásticas (Moore, 1990). Nos casos relatados, o principal material ingerido e retirado do intestino dos cavalos foram sacolas plásticas, provavelmente por estes animais alimentarem-se de restos de feira acondicionados em sacolas plásticas e permanecerem alojados em terrenos baldios e lixões, onde a presença é comum.

Ocasionalmente, dependendo da localização da massa, esta poderá ser palpada no toque retal, auxiliando o diagnóstico (Thomassian, 2005; Rhoads 1999). Outro método diagnóstico é a ultrassonografia abdominal. Este exame de imagem é importante no momento de decisão para o tratamento clínico ou cirúrgico, pois por meio deste é possível mensurar parâmetros como grau de distensão de alças, espessura da parede intestinal, peristaltismo e alterações na ecogenicidade do líquido peritoneal (Viljoen et al., 2010). Essas técnicas diagnósticas foram eficientes em quatro animais relatados, e em outros dois, o diagnóstico teve que ser confirmado por celiotomia.

Grande parte das obstruções em cólon menor ocorre na porção proximal, dificultando exposição do segmento (Pierce, 2009). Em um estudo, seis cavalos com corpo estranho em cólon menor foram eutanasiados no transoperatório devido ruptura do segmento afetado durante a manipulação (Hassel et al., 1997). No presente trabalho, dos cinco animais, dois vieram à óbito pela dificuldade relatada em literatura de exposição do cólon menor e do cólon transverso, em ambos os segmentos haviam áreas de necrose e no momento de exteriorização houve ruptura. Um animal 
foi à óbito ao final do procedimento cirúrgico, devido à parada cardiorrespiratória decorrente à broncopneumonia, esta, deu-se por administração medicamentosa por falsa via realizada por leigo. Outros dois animais, um que obteve resolução clínica, recebeu alta no dia seguinte e o animal submetido a procedimento cirúrgico recebeu alta no $15^{\circ}$ dia de pós operatório e não houve nenhuma complicação.

O prognóstico de animais com obstrução intestinal ocasionada por corpo estranho varia com o tempo de evolução, grau de isquemia e distensão do segmento comprometido. O diagnóstico precoce e o encaminhamento emergencial para celiotomia exploratória também são cruciais com relação à sobrevida dos pacientes (Hassel, 1997). Comparando ao que o autor relata, as informações foram fidedignas com relação ao prognóstico dos animais atendidos e relatados neste trabalho, onde os que apresentaram sinais clínicos há mais de dois dias vieram a óbito.

\section{CONCLUSÃO}

Conclui-se com este trabalho que a principal causa de síndrome cólica em equinos carroceiros de Curitiba e região metropolitana é devido a ingestão de corpos estranhos. A causa primária desta afecção deve-se ao fato de o manejo alimentar destes equinos carroceiros ser ineficiente e as condições ambientais em que vivem serem precárias, facilitando a ingestão de materiais sintéticos (sacolas) por esses animais.

Neste estudo, o reto e cólon menor foram os principais locais onde os corpos estranhos foram encontrados e o exame ultrassonográfico e palpação retal quando utilizados mostraram-se eficazes como auxilio diagnóstico nestes casos, levando à escolha do tratamento cirúrgico.

\section{NOTAS INFORMATIVAS}

Reservado ao parecer CEUA.

\section{REFERÊNCIAS}

ANDRADE, R. L. F. S.; SOBRAL, J. C.; SILVA, K. M. H. Avaliação Clínica, hematológica e parasitária em equinos de tração na cidade de Aracaju, Sergipe. Acta Veterinaria Brasilica. v.3, n-3, p. 138-142, 2009.

AUER, J. A; STICK, J. A. Equine surgery. In:Large Intestine. 4 ed. St. Louis, Missouri, p. 454-489, Elsevier. 2012.

DEARO, A. C. DE O. et al. Surgical Removal of a Descending (Small) Colon Foreign Body through a Secondary Paramedian Approach. Journal of Equine Veterinary Science, v. 29, n. 3, p. 155-159, 2009.

DORAN, R. Field management of simple intestinal obstruction in horses. Compendium of Continuing Education for the Practising Veterinarian. v. 15, p. 463-471. 1993.

FERREIRA, C.; PALHARES, M. S.; MELO, U. P.; BRAGA, C. E.; FANTINI, D.; SILVA FILHO, J. M. Compactações do trato gastrointestinal em equinos: achados clínicos de 64 casos. Anais da VIII Conferência Sul-americana de Medicina Veterinária. Rio de Janeiro. CD ROM, 2008.

GONÇALVES. S.; JULLIAND, V.; LEBLOND, A. Risk factors associated with colic in horses. Veterinary Research. v.33, p. 641-652, 2002.

HASSEL, D. M.; SYNDER, J. R.;
LANGER, D. M.; DRAKE, C. M.;
YARBROUGH,
T. 
Enterolithiasis: A review and Retrospective Analysis of 900 Cases (1973-1996). Proceedings of the Annual Convention of the AAEP, Nashville, v. 43, p.246-247. 1997.

MOORE, J. N. Diseases of the small colon and rectum. In: WHITE, N. A. The equine acute abdomen. Philadelphia: Lea \& Febiger, p. 392-402. p. 392-402.

OLIVEIRA, L. M.; MARQUES, R. L.; NUNES, C. H.; CUNHA, A. O. Carroceiros e equídeos de tração: Um problema sócio ambiental. Revista online caminhos da geografia. Uberlândia, v. 8, n. 24, p.204-216, 2007.

PIERCE, R. L. Enteroliths and Other Foreign Bodies. Veterinary Clinics of North America: Equine Practice, Knoxville, v. 25, p. 329-340. 2009.

RHOADS, W. S. Small colon impactions in adults horses. of Continuing Education for the Practising Veterinarian. v. 21, p. 770-775, 1999.

THOMASSIAN, A. Enfermidades dos cavalos. 4 ed. São Paulo: Varela, 2005.

VILJOEN, A.; SAULEZ, M. N.; CARSTENS, A.; GUMMOW, B. The impact of ultrasound during emergency after-hour admissions of horses. Journal of the South African Veterinary Association. v.81, n.4, 216-218. 2010. 